\title{
VIBRATION ANALYSIS OF CI ENGINE USING FFT ANALYZER
}

\author{
Namdev A. Patil ${ }^{1}$, Laukik P. Raut ${ }^{2}$ \\ ${ }^{I}$ Student, M. Tech CAD/CAM, G. H. Raisoni College of Engineering, Nagpur, India \\ namdevpatil007@gmail.com \\ ${ }^{2}$ Assistant Professor, G. H. Raisoni College of Engineering, Nagpur, India \\ rautlaukik@gmail.com
}

\begin{abstract}
In automobile industry, the vibrations generated in the IC engine affects the performance of the vehicle and quality of comfort while riding the vehicle. The factors which are affected under continuous vibration of IC engine are drivability, stability and comfort. All these factors are reducing while there is an increase in vibrations produced by the engine. Reciprocating as well as rotating parts of the engine are producing vibrations continuously in the internal combustion engine. The inertial forces are produced by these reciprocating and rotating parts. These inertial forces are changing with compression and combustion characteristics inside the engine. The vibrations produced by the engine can be minimized by reducing those unbalanced forces generated during its functioning, otherwise anti vibration mounts are placed in between engine and its base. Many researchers have performed experimentations to see reasons behind the vibration generations also to reduce vibrations at interface between engine and its base. In this paper a thorough collection of data related to engine vibrations is made to provide a platform for future work. It encompasses various work carried on engine rigid body modeling. The paper is framed as engine rigid body modeling, engine vibrations in detail and at last some experimental work performed on a single cylinder diesel engine to measure vibrations using FFT spectrum analyzer.
\end{abstract}

Keywords: Internal combustion engine, Engine Rigid Body, Vibration, FFT Analyzer.

\section{INTRODUCTION}

The internal combustion engine design, itself is a complex task as it includes multiple parts of various sizes assembled together. The internal combustion engine is required to be designed carefully so that the unbalanced forces generated by the engine parts are reduced. If the design is not optimum it will generate more vibrations and are transmitted to supporting structure. It affects driver stability, drivability and comfort. Taking into account the consumer aspirations and surrounding considerations vibration reduction is at most important phenomenon. Four major causes for overall vibration behavior of IC engine are variation in gas pressure in each cycle, impact forces due to reciprocating parts, unbalanced rotating and reciprocating parts and mount structural characteristics. During working of engine speed, load on the engine is varying depending upon need. Due to which fuel supply and combustion characteristics also changes. Major components of an IC engine are continuously having relative motion in between them. The inertial forces changes with respect to compression and combustion variation inside the cylinder. It is definite that inertial forces give rise to unbalanced forces and they are fluctuating with speed of the engine, fuel supplied and combustion characteristics of the fuel. Hence for fulfilling consumer satisfaction and calculate the vibration output and its minimization, a mathematically accurate design model along with its simulation is at most required.

IC engine produces mainly two types of vibrations i.e. longitudinal and torsional vibrations. In which reciprocating behavior of the engine results some torsional vibration continuously. In compression stroke when piston moves towards top dead centre the cylinder pressure increases. As then ignition and combustion of the fuel occurs pressure again increases and then pressure reduce with piston movement towards bottom dead centre. The pressure generated due to combustion of fuel exerts tangential force on the piston that does required work and crankshaft speed increases. So the crankshaft speed is increases in combustion stroke where as decreases during compression stroke respectively. This changing speed of the crankshaft gives rise to torsional vibrations for crankshaft. Thus the change in combustion pressure during downward motion and changing inertial motion during upward motion of the piston gives rise to unbalanced forces on the engine block. These are considered to be responsible for generating the longitudinal vibrations and these are measured in three perpendicular directions. These above discussed main two types of the vibrations can be minimized by reducing unbalanced forces also by putting mounts.

Thus to measure and minimize the engine vibrations a dynamic approach is needed. To discuss various methods used and the assumptions used a collection is done on engine as a rigid body, and its vibrations. The discussion followed by an experimental analysis. The experimentation is conducted on a single cylinder diesel engine.

\section{ENGINE AS A RIGID BODY}

In the internal combustion engine there are various parts such as piston, engine block, connecting rod, engine head, crankshaft, cam shaft, flywheel, valves, pulleys etc. Among 
all these parts few parts are taken as vibration generating parts by the research scholars and industry experts. There are four major components which generate vibrations by producing unbalanced forces during cycle are piston, crankshaft, engine block and connecting rod. As these components are interconnected with each other, produced unbalancing forces are passed to the engine parts such as building block of engine and to the contacting structure. Many researchers developed and studied various mathematical rigid body models to calculate the unbalanced forces during engine cycle, by making use of multibody modeling. Hoffman and Dowling [1] performed thorough experimentation on the diesel engine with six cylinders to calculate vibrational force components in three orthogonal directions at three engine mounts. Hoffman and Dowling [2] evolved seven DOF model for engine vibrations with low frequency, which assumes two way coupling. Finally they have compared results of this with model having one way coupling assumption. Hoffman and Dowling [3] managed to get a model with 7 DOF which is conserving energy also it is giving features of overall IC engine vibration output.

Deana M. Winton and Dowling [4] performed an experiment with 6 cylinder diesel engine to measure vibrations of engine building block with its rigid body analysis. Zeng-Dong Ma and Perkins [5] found the motion equations used for important parts of the IC engine by using method of recursive formulation. They prepared computer program by using $\mathrm{C}$ language and FORTRAN sub routines to derive the equations of motion automatically. Tsuneo $\mathrm{T}$. and Tetsuya S. [6] gave a vibration reduction method during idling condition of a heavy duty truck engine. They have developed FEA model of full engine vibrations. $T$. Ramachandran et al. [7] used ant colony optimization method for the minimization of the internal combustion engine forces and displacements. They considered a four cylinder IC engine as a rigid body. Mathematical model is developed and forces and displacements are minimized by optimizing the crank angles.

The internal combustion engine looks simple but it is highly complicated machine containing hundreds of components which have to perform its functions satisfactorily to produce required power output. In such a complicated machine while it is running components have relative motion with respect to each other producing internal vibrations. The collective effects of these relative motions are also responsible for external vibrations of the internal combustion engine as a whole. Here by using the concept of rigid body modeling the internal vibrations can be excluded and focus will be on external vibrations only. The experimentation included in this paper to obtain vibrations of a single cylinder diesel engine and its results can be compared with vibrations obtained by using dynamic analysis of engine as a rigid body.

\section{ENGINE VIBRATION}

IC engine composed of various parts produces vibratory forces which are as a result of the uneven forces as of the engine components throughout the operation. Engine produces longitudinal as well as torsional vibrations at the engine supports. Engine loads and changing combustion pressures produces torsion vibration at crankshaft of engine. Longitudinal vibrations at the engine block are produced with reciprocating as well as rotating sub parts of the engine.

Chung Ha et al. [8] developed a simplified method to get vibration amplitudes generated by a four cylinder engine which is supported on a viscoelastic mounts, by modeling engine components as rigid body connected to rubber mounts. Snyman et al. [9] provided method of reduction of engine vibration in a 4 cylinder mounted IC engine. They developed a mathematical model by taking lead angles and balancing masses as propose independent variables and the intended function is vibrating forces transmit to the mounts at engine base. The method used to lessen the intended function. Zhang Juhong and Han Jun [10] found change in engine design for a totally new engine which could lessen noise with low frequency and the vibration lower than the presented production also optimizing its noise as well as vibration characteristics. P. Charles et al [11] studied a fault detection technique for an internal combustion diesel engine depending on torsional vibration of crank shaft inside the engine. In this paper scholars make use of encoder signal to check speed of a shaft and produced the instantaneous angular speed (IAS) waveform. They supervised a 16 cylinder diesel engine by using IAS and FFT (Fast Fourier Transform). They found that FFT improves signal processing to get the IAS signals. Fredrik Otsman et. al. [12] have given method of reducing torsional vibration during running of a common railway diesel engine of reciprocating type. They found that no uniform torque would be the reason behind greater than before torsional vibration and stresses developed inside various parts of the IC engine. They finally concluded that this active cylinder scheme reduces the torsional vibrations. Rajendran and Narasimhan [13] have focused on combined torsional as well as vibrations with no bending mainly in the single cylinder engine crankshaft. They have developed finite element models and concluded that the introduction of inertial coupling affects the free vibrations characteristics. Under such circumstances they have concluded that in modeling of crankshaft, the pure torsional system may have considerable errors. H. Ashrafioun et al. [14] have looked on response in terms of frequency for a engine of aircraft to measure exciting forces. The transmitted forces minimization was critical as far as location, orientation and type of mount is concerned. They have also considered most of the applicable Vibration Isolation Systems. Conti and Bretl [15] have created a totally renovated method for getting the investigative model of rigid body on its supportive mounts and a way for data acquisition system. Using external impact excitation in a vibration analysis test through mounts they found mass of a engine rigid body yielding properties and mounts stiffness properties from data extracted during experimentation. They have evaluated location of centre of gravity, mass moment, principle axes of inertia as well as triaxial stiffness for mounts with mass of complete system. Nader Vahadati and L. Ken Laudrebaugh Saunders [16] have tested a machine with high frequency performance 
using rubber mounts. They have presented a mathematical comprehensive model of a test machine having large frequency. They have compared outputs of both mathematical model and simulation at the frequency of 5000 Hz. Accordingly they implemented changes in design of fixtures, mass and mounts as well. They found that the designed fixture should be of minimum weight.

By looking into the different methods of vibration analysis of above discussed research scholars, a vigorous and accurate mathematical model and with simulation is required to cover gap between vibration modeling and its isolation from its base. The internal combustion engine itself is a complicated design containing many components; at most care is required in developing such multibody modeling and simulation.

\section{EXPERIMENTATION}

In the experimentation the longitudinal vibration acceleration signatures are measured in three orthogonal directions $\mathrm{X}, \mathrm{Y}$ and $\mathrm{Z}$ directions respectively on a single cylinder Kirloskar diesel engine by using FFT spectrum analyzer setup. In the experimentation while taking readings an acceleration transducer having piezoelectric sensor is used, this is placed at three different locations to get signatures in $\mathrm{X}, \mathrm{Y}$ and $\mathrm{Z}$ directions. All vibrations measured are for $100 \%$ diesel fuel that is without blending with any kind of biodiesel. While taking readings diesel engine is run idle for 2 minutes without load and then readings are taken. As the test rig is attached to the engine other observations are also taken and enlisted in the table.

Parameters focused in the experimentation are as follows:-

$>$ Mainly Rotating and Reciprocating members produces Unbalanced Inertial Forces, Torsion are responsible for vibration generation.

$>$ Independent parameters used in the experimentation are as follows:

- Load on the engine.

$>$ Output parameter measured is Vibration Acceleration Signatures.

$>$ Also some other measurements on test rig are :-

- Speed of the engine.

- Fuel Rate.

- Air flow rate inside the engine.

- Temperature of Exhaust gas.

The loading on the engine is done by using Eddy current Dynamometer. The load is increased in the steps zero, five, ten percent and so on up to thirty percent. Due to engine operating constraints the load is not increased above thirty percents.

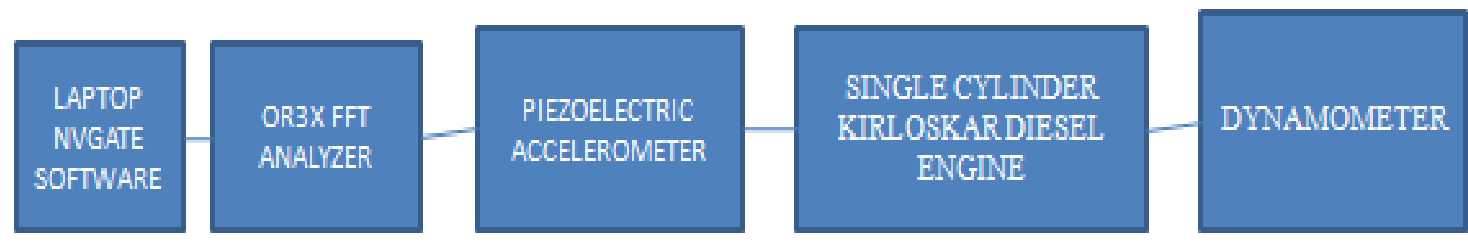

Figure 1. Schematic Line Diagram of Experimental Setup

Equipments used in the experimentation are enlisted below

:-

1. Single Cylinder Diesel Engine

2. OR3X Analyzer

3. PC with NV Gate Software installation

4. Ethernet link

5. Transducer: Piezoelectric Accelerometer

6. Tachometer

Engine Specifications Details are as follows:-

1. Kirloskar Single Vertical Cylinder Diesel Engine

Power $=18 \mathrm{BHP}(7.4 \mathrm{KW})$

Loading = Eddy Current Dynamometer.

Maximum Torque $=32 \mathrm{Nm}$

Stroke $=116 \mathrm{~mm}$

Compression Ratio $=17.5: 1$

Engine speed $\mathrm{rpm}=1500$

Bore $=102 \mathrm{~mm}$

Specific Fuel Consumption $=0.251 \mathrm{~kg} / \mathrm{Kw}-\mathrm{hr}$.

2. FFT Analyzer Specifications:

OR3X Analyzer

OROS 3 Series / NV Gate software

\section{Accelerometer with Piezoelectric Sensor}

4. Digital Tachometer

RMS Acceleration = Square root (summation of square of amplitudes divided by no. of observations).

Table 1. Observation table

\begin{tabular}{|c|c|c|c|c|c|c|}
\hline 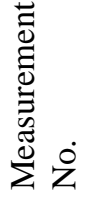 & $\begin{array}{l}0 \\
0 \\
0 \\
0 \\
0 \\
0\end{array}$ & 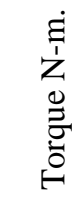 & 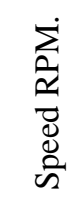 & 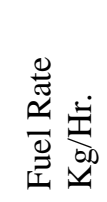 & 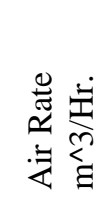 & 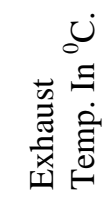 \\
\hline 1 & 0 & 0 & 1550 & 0.78 & 46 & 256 \\
\hline 2 & 5 & 1.6 & 1541 & 0.78 & 37 & 286 \\
\hline 3 & 10 & 3.2 & 1535 & 0.84 & 66 & 307 \\
\hline 4 & 15 & 4.8 & 1530 & 0.96 & 122 & 338 \\
\hline 5 & 20 & 6.4 & 1523 & 1.14 & 130 & 365 \\
\hline 6 & 25 & 8.0 & 1515 & 1.38 & 137 & 410 \\
\hline 7 & 30 & 9.6 & 1490 & 1.50 & 150 & 489 \\
\hline
\end{tabular}


Vibration acceleration signatures are obtained and root mean square acceleration values are measured.

\section{Longitudinal Vibrations in Y Direction:}

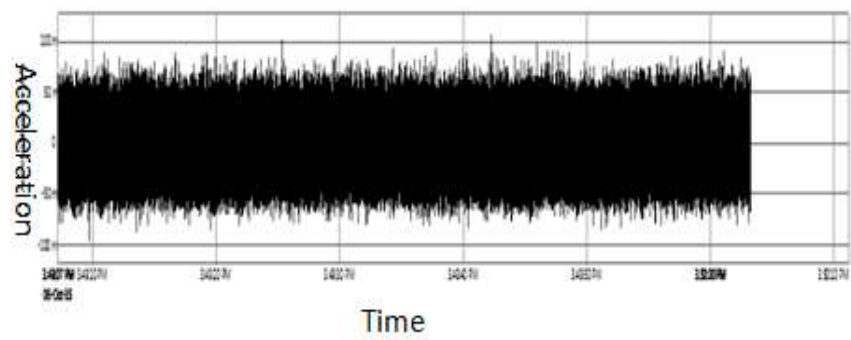

Figure 2. Time vs Acceleration measurement 1 in $\mathrm{Y}$ direction

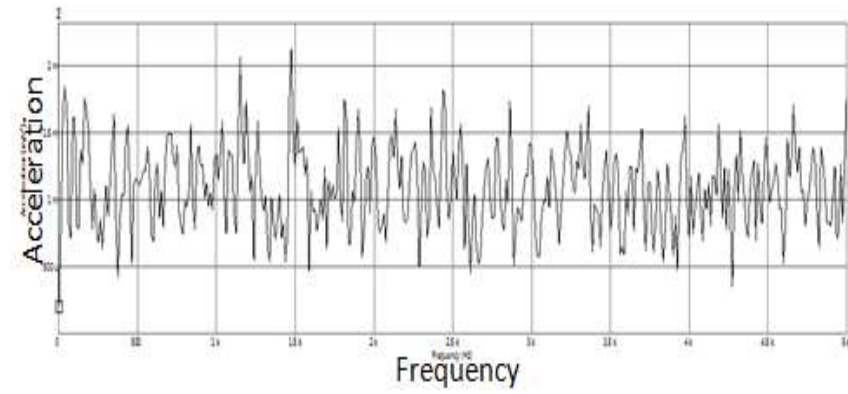

Figure 3. Frequency vs Acceleration Measurement 1 in $\mathrm{Y}$ direction

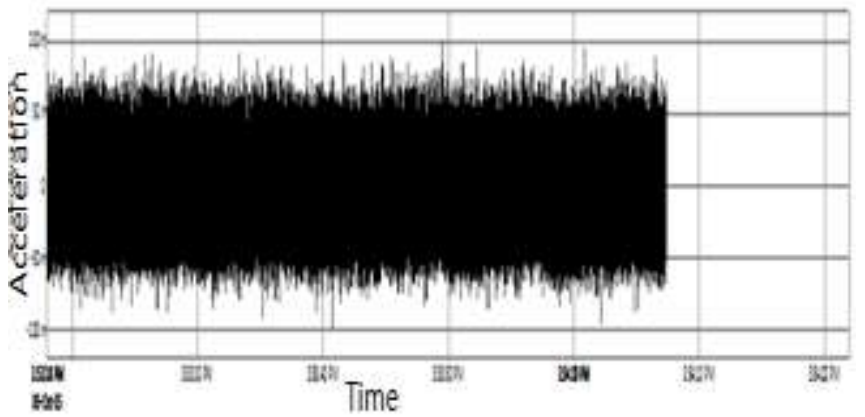

Figure 4. Time vs Acceleration Measurement 2 in $\mathrm{Y}$ direction

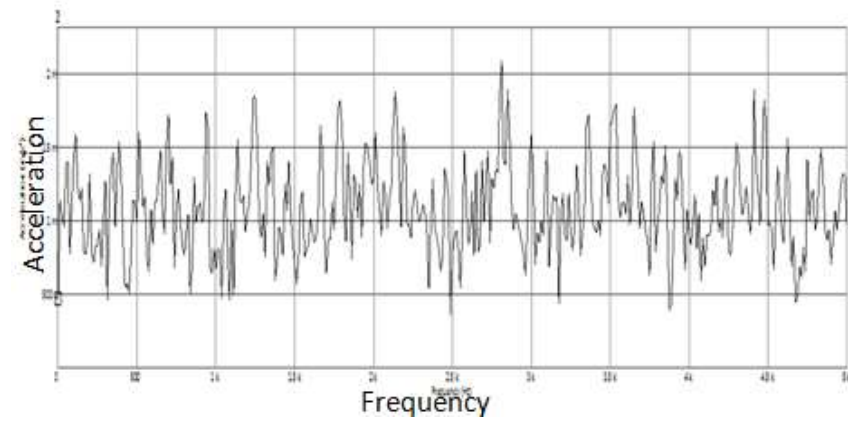

Figure 5. Frequency vs Acceleration Measurement 2 in Y direction

By taking the signatures of acceleration, vibration behavior in $\mathrm{Y}$ direction is observed. Observations for vibrations in $\mathrm{Y}$ direction are:

- The vibrations amplitude ranging from $50-130 \mathrm{~m} / \mathrm{s}^{2}$.
- Peak value of acceleration $=130 \mathrm{~m} / \mathrm{s}^{2}$.

- RMS Acceleration amplitudes are 61.5, 48.8, 46, 44.5, $42.4,42 \mathrm{~m} / \mathrm{s}^{2}$.

- Highest acceleration amplitudes are at $1500 \mathrm{~Hz}, 2700 \mathrm{~Hz}$, $3300 \mathrm{~Hz}, 3200 \mathrm{~Hz}, 2600 \mathrm{~Hz}, 15 \mathrm{~Hz}$, and $700 \mathrm{~Hz}$ with increasing loads.

- Amplitude of vibration are directly varying with respect to load.

- As the speed of engine decreases, amplitude of vibration decreases.

- As Fuel rate increases there is decrease in vibration amplitudes.

\section{Longitudinal vibrations in $\mathrm{X}$ direction:}

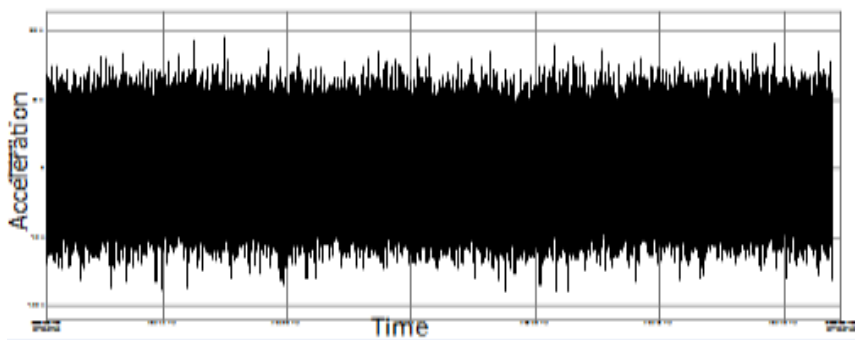

Figure 6. Time vs Acceleration Measurement 1 In X direction

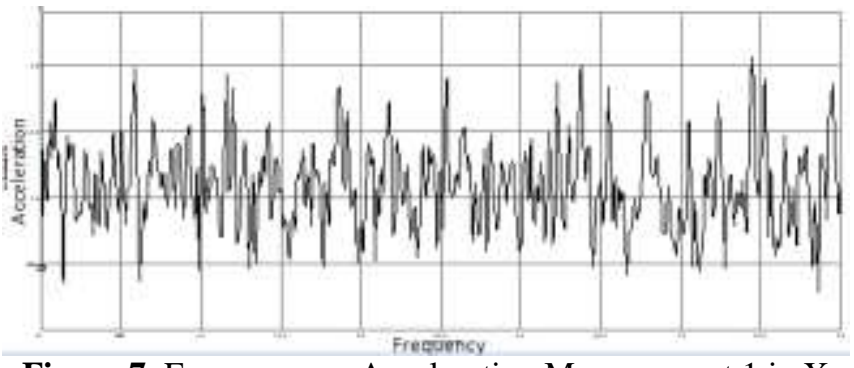

Figure 7. Frequency vs Acceleration Measurement 1 in X direction

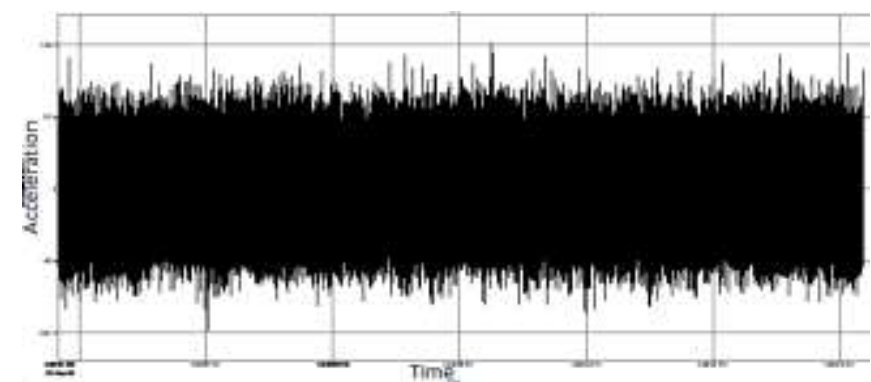

Figure 8. Time vs Acceleration Measurement 2 in $X$ direction

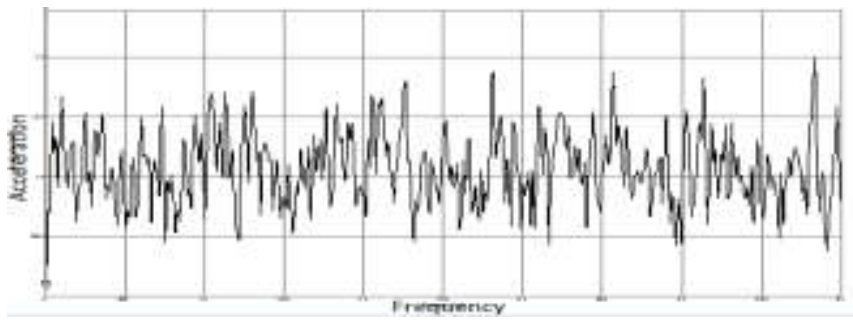

Figure 9. Frequency vs Acceleration Measurement 2 in $X$ direction 
By taking the signatures of acceleration, vibration behavior in $\mathrm{X}$ direction is observed. Observations for vibrations in $\mathrm{X}$ direction are:

- The vibrations amplitude ranging from $30-110 \mathrm{~m} / \mathrm{s}^{2}$.

- Peak value of acceleration $=110 \mathrm{~m} / \mathrm{s}^{2}$.

- RMS Accelerations are 69.3, 74.9, 78.4, 82.73, 83, $83.43,83.43 \mathrm{~m} / \mathrm{s}^{2}$.

- Highest acceleration amplitudes are at $4300 \mathrm{~Hz}, 4800 \mathrm{~Hz}$, $3300 \mathrm{~Hz}, 4900 \mathrm{~Hz}, 200 \mathrm{~Hz}, 2100 \mathrm{~Hz}$, and $700 \mathrm{~Hz}$ with increasing loads.

- Here also increasing load gives increase in vibration amplitudes.

- In this case engine speed decreases then amplitude of vibration increases.

- Vibrations of the engine increases in $\mathrm{Z}$ direction as the Fuel Rate is increasing.

\section{Longitudinal vibrations in $\mathrm{Z}$ direction:}

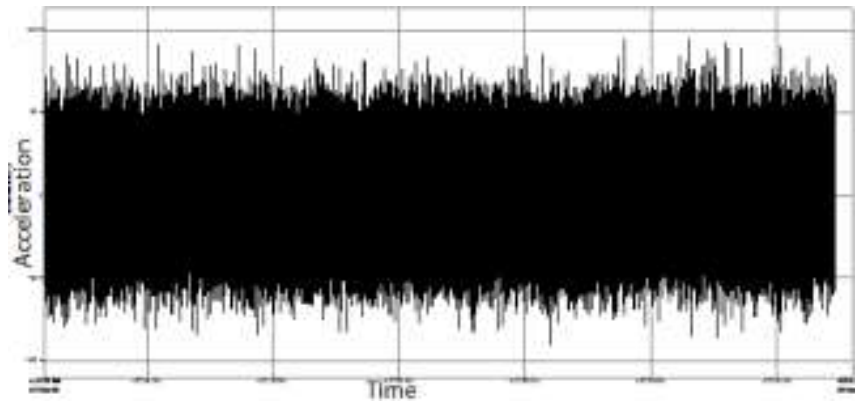

Figure 10. Time vs Acceleration Measurement 1 In Z direction

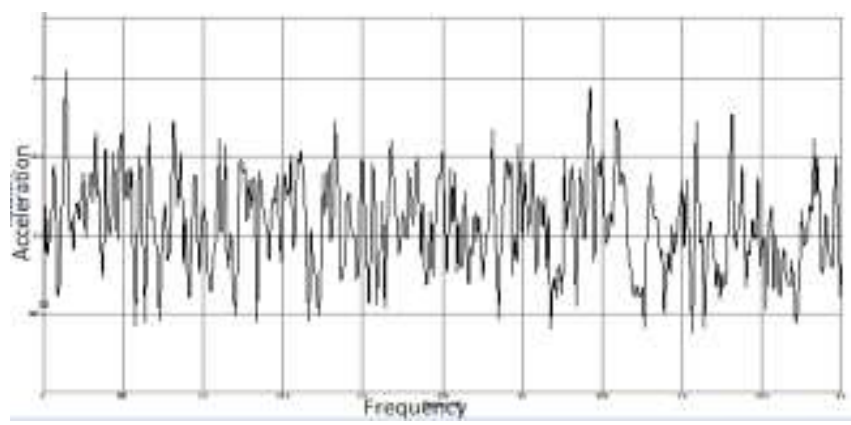

Figure 11. Frequency vs Acceleration Measurement 1 in $\mathrm{Z}$ direction

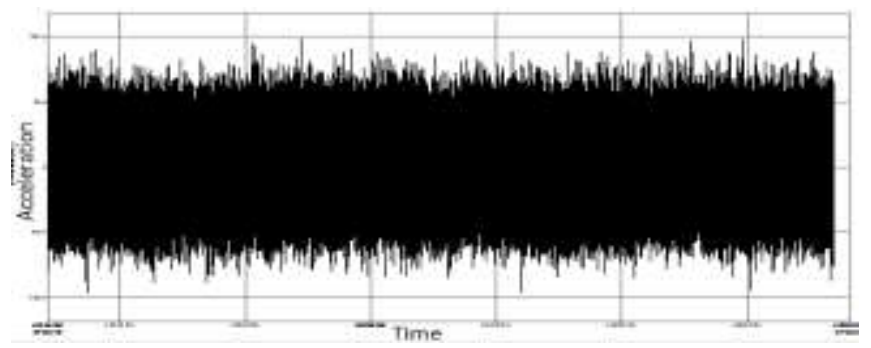

Figure 12. Time vs Acceleration Measurement 2 In Z direction

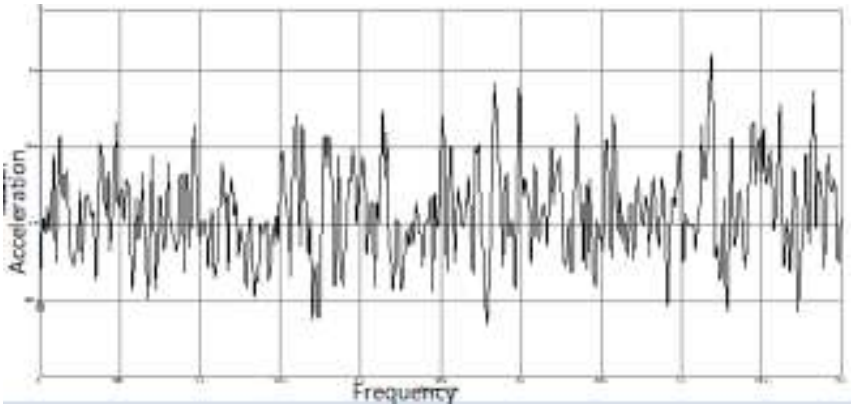

Figure 13. Frequency vs Acceleration Measurement 2 in $\mathrm{Z}$ direction

By taking the signatures of acceleration, vibration behavior in $\mathrm{Z}$ direction is observed. Observations for vibrations in $\mathrm{Z}$ direction are:

- The vibrations amplitude ranging from $30-105 \mathrm{~m} / \mathrm{s} 2$.

- Peak value of acceleration $=105 \mathrm{~m} / \mathrm{s} 2$.

- RMS Accelerations are 67.17, 74.95, 75.66, 76.36, $77.78,77.8,78 \mathrm{~m} / \mathrm{s} 2$.

- Highest acceleration amplitudes are at $200 \mathrm{~Hz}, 4250 \mathrm{~Hz}$, $3700 \mathrm{~Hz}, 2600 \mathrm{~Hz}, 5000 \mathrm{~Hz}, 2100 \mathrm{~Hz}, 3500 \mathrm{~Hz}$ frequencies with increasing loads from 0 to 30 percents.

- Load on engine increased then amplitude of vibration also increased.

- Speed of engine and amplitude of vibration are changing with indirect proportionality.

- As Fuel rate and the amplitude of vibration again directly proportional to each other.

\section{CONCLUSION}

In the vibration analysis of internal combustion (IC) engine the non detrimental technique like FFT spectrum analysis method is very fruitful. By making use of engine multibody rigid modeling a mathematical model generation becomes achievable as well as simplified. There may be number of such models can be developed by making use of different initial conditions while considering engine as a rigid body. Now the observations of conducted experimentation are:-

- Magnitude of Vibration depends upon selection of axis of engine for acquisition of signatures. In above the vibrations are greater in $\mathrm{Y}$ direction as compared with $\mathrm{X}$ and $\mathrm{Z}$ direction.

- Magnitude of vibration depends upon engine speed. As the speed of engine decreases the vibration acceleration amplitude also decreases in $\mathrm{Y}$ direction but increases in $\mathrm{X}$ and $\mathrm{Z}$ direction.

- Vibration Amplitudes also depends upon load on engine. As load on engine increases vibration acceleration amplitude also decreases in $\mathrm{Y}$ direction but increases in $\mathrm{X}$ and $\mathrm{Z}$ direction.

- With increase in load on engine the fuel rate increases, vibrations in $\mathrm{Y}$ direction decreases but increases in $\mathrm{X}$ and $\mathrm{Z}$ direction.

In future time, a robust and accurate mathematical model with its prior simulation is required further more to bridge the gaps in vibration analysis of such a complicated power unit like the internal combustion engine. 


\section{REFERENCES}

[1] D. M. W. Hoffman, D. R. Dowling, 'Limitations of rigid body descriptions for heavy-duty diesel engine vibration', ASME Journal of Engineering for Gas Turbine and power 121: 197-204, 1999.

[2] D. M. W. Hoffman, D. R. Dowling,' Fully coupled internal combustion engine dynamics and vibration- part II: Model-Experiment comparison', ASME Journal of Engineering for Gas Turbine and power 123: 685-692, 2001. [3] D. M. W. Hoffman, D. R. Dowling, 'fully coupled internal combustion engine dynamics and vibration- part I: Model development', ASME Journal of Engineering for Gas Turbine and power 123: 677-684, 2001.

[4] Deana M. Winton, David R. Dowling, 'Modal content of Heavy-duty diesel engine block vibration' SAE Paper\#971948,1997.

[5] Zheng-Dong Ma, Noel C. Perkins, 'An efficient multibody dynamics model for internal combustion engine systems', Multibody System Dynamics 10: 363-391,2003.

[6] Tsuneo Tanaka, Mitsuo Iwahara, Tetsuya Sakai, 'The optimization of engine vibration reduction by simulation analysis.' SAE\#962203, 1996.

[7] T. Ramachandran, K. P. Padmanaban and J. Vinayagamoorthy, 'Ant Colony Optimization for the Minimization of Internal Combustion Engine Forces and Displacements', Emerging Trends in Science/10.1007/97881-322-1007-8_2, Springer India 2012.

[8] Chung-Ha Suh, Clifford G. Smith, 'Dynamic simulation of engine mount system' 'SAE Paper\#971940.

[9] J. A. Snyman, P. S. Heyns, P. J. Vermeulen, 'Vibration isolation of a mounted engine through optimization.' Mech. Mach. Theory 30 (1): 109-118.

[10] Zhang Juhong, Han Jun, 'CAE process to simulate and optimize engine noise and vibration' Mechanical Systems and signal processing 20: 1400-1409, 2006.

[11] P. Charles, Jyothi Sinha, F. Gu, L. Lidstone, A. D. Ball, 'Detecting the crank shaft torsional vibration of diesel engines for combustion related diagnosis' J. of sound and vibration 321: 1171-1185, 2009.

[12] Fredrik Ostman, Hanna T. Toivonen, 'Active vibration control of reciprocating engines' Control Engineering Practice16:78-88, 2008.

[13] S. Rajendran, M. V. Narasimhan, ' Effect of inertia variation due to reciprocating parts and connecting rod on coupled free vibration of crank shaft' ASME Journal of Engineering for Gas Turbine and power $119: 257-263$.

[14] Ashrafiuon, H., and Natraj, C, 'Dynamic Analysis of Engine-Mount Systems', ASME J. Vibr. Acoust, 114: 7983.

[15] P. Conti, J. Bretl, 'Mount stiffness and inertia properties from modal test data', ASME Journal of Vibrations and Acoustics, Stress and Reliability in Design 111: 134-141.

[16] Nader Vahdati, L. Ken Lauderbaugh Saunders, High frequency testing of rubber mounts, ISA Transactions 41: $145-154,2002$. 